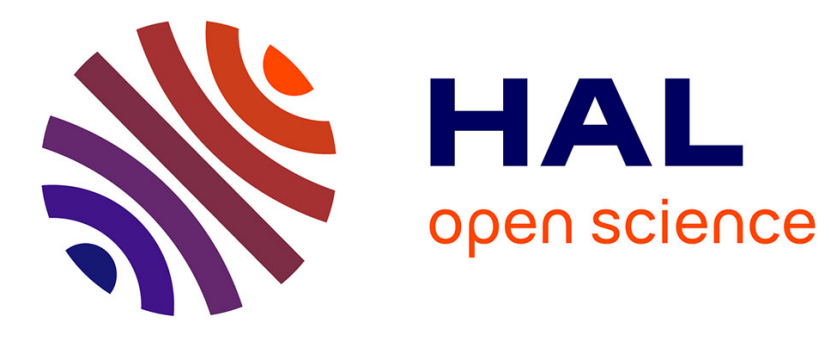

\title{
Sustainable Development Within Enterprise Architecture
}

\author{
Daniel Alves, Renato De Campos, Fernando B. Souza
}

\section{To cite this version:}

Daniel Alves, Renato De Campos, Fernando B. Souza. Sustainable Development Within Enterprise Architecture. IFIP International Conference on Advances in Production Management Systems (APMS), Sep 2016, Iguassu Falls, Brazil. pp.552-559, 10.1007/978-3-319-51133-7_66 . hal-01615769

\author{
HAL Id: hal-01615769 \\ https://hal.inria.fr/hal-01615769
}

Submitted on 12 Oct 2017

HAL is a multi-disciplinary open access archive for the deposit and dissemination of scientific research documents, whether they are published or not. The documents may come from teaching and research institutions in France or abroad, or from public or private research centers.
L'archive ouverte pluridisciplinaire HAL, est destinée au dépôt et à la diffusion de documents scientifiques de niveau recherche, publiés ou non, émanant des établissements d'enseignement et de recherche français ou étrangers, des laboratoires publics ou privés. 


\title{
Sustainable Development within Enterprise Architecture
}

\author{
Daniel F. R. Alves, Renato de Campos, and Fernando B. Souza \\ São Paulo State University, São Paulo, Brazil \\ danielfrancora@gmail.com \\ \{rcampos, fbernardi\}@feb.unesp.br
}

\begin{abstract}
Enterprises are looking for improvements in their processes, products and services, causing them to become more complex mainly due to the amount of information and requirements involved. At same time, governments and costumers are more conscious about Sustainable Development requirements. Enterprise Architectures supports the analysis, simulation, automated systems projects, distribution of responsibilities and authorities, aimed at reengineering or improvement of companies processes. However, they do not seem to contemplate the requirements related to Sustainable Development in a systemic and integrated way. This paper discusses the derivation and incorporation of Sustainable Development requirements into Enterprise Architecture Frameworks (EAF). Then, this works presents some initial guidelines to extend components of GERAM with ISO standards and frameworks related to sustainability..
\end{abstract}

Keywords: Sustainable development - Enterprise architecture · ISO . GERAM

\section{Introduction}

One way to better analyze, design and integrate enterprise process activities as well as provide support for decision making during production management is to use enterprise models. In other words, enterprise modeling can provide support to the entire life cycle in developing company systems from the definition of enterprise strategies and requirements to design and implementation of the systems [1]. There are several Enterprise Architecture Frameworks (EAF) for Enterprise Engineering, such as PERA (Purdue enterprise architecture framework), CIMOSA (Open system architecture for computer integrated manufacturing), ARIS (Architecture for information system), and TOGAF (The open group enterprise architecture framework). Although neither of them explicitly and systematically consider in a systemic and integrated way the requirements Sustainable Development (SD).

Enterprises use some methods to reach the SD using standards and systems, such as ISO 9001, ISO 14001, and ISO 26000 to achieve the economic, environmental and social requirements of SD. Nevertheless, it seems to be necessary 
consider the SD requirements into an EAF in a more explicit and systematic way, helping the companies to build their sustainable model.

Thus, this article aims to investigate the support of SD requirements by an EAF and its components. It is discussed the derivation and incorporation of Sustainable Development (SD) requirements into Enterprise Architecture Frameworks (EAF), and is presented some initial guidelines to extend components of GERAM (as GERA) with ISO standards and frameworks related to sustainability.

To accomplish these proposal, this research made a literature review of all important topics, creating through that a conceptual framework with connections between multiple bodies of literature and knowledge bases to make our proposal [2,3].

In that sense, searches were carried out at scientific databases such as Web of Science, Scopus, Springer Link, John Wiley \& Sons, Google Scholar, Web of Knowledge and IEEE Xplore, using as keywords the terms: Enterprise Integration, Enterprise Engineering, GERAM, Enterprise Architecture, Sustainable Development, Enterprise Architecture Frameworks, ISO 9001, ISO 14001, ISO 26000 and GRI (Global Reporting Initiative). All of them performed using the default search engine for each data-base without any customization on the search engines, selecting the results through the reading of their abstracts.

Section 2 of this paper presents a literature review of standards and frameworks related to Sustainability, followed by section 3 with a review about Enterprise Architecture Frameworks. In section 4 it is developed a cross analysis of standards and frameworks with components of an enterprise architecture and requirements for sustainable development. Then, guidelines are described to extend components of GERAM with ISO standards and frameworks related to sustainability. Section 5 concludes this paper, by presenting the main results of this research and by discussing topics for future study.

\section{Standards and Frameworks for Sustainability}

The standards ISO 9001, ISO 14001 and ISO 26000 have been proposed to adopt SD and they became important for enterprises seeking Sustainable Development (SD) commitment $[4,5,6]$. ISO Standards such as ISO 9001, ISO 14001 and ISO 26000 became a source of technological knowledge in the economic, environmental and social dimensions, respectively [7].

ISO 9001:2000 covers quality, customer satisfaction, reduction of waste and customer complaints, standardization of work processes and communication improvement as well as an increase in market share. ISO 9001:2000 is based on a review of the twenty clauses of ISO 9001:1994, resulting in five key management requirements [8]. ISO 14000 include aspects of quality and the environment, mitigating the emission of effluents, reducing the environmental impact by improving customer satisfaction [7]. ISO 14000 consists of seventeen clauses divided into five categories. Each clause was written to suit a wide variety of enterprises [5,9]. ISO 26000, unlike ISO 14001 and ISO 9001, this standard provides guidelines 
rather than requirements, so it cannot be certified $[4,10]$. The standard considers that the enterprise has responsibility for the impacts of its decisions and activities on society and the environment. Thus it must be transparent and ethical, in order to contribute to the $\mathrm{SD}$, health and well-being of society. The structure of ISO 26000 consists of seven clauses [11].

Following these efforts, the GRI framework emerges with guidelines that consist of recommendations, principles, and a standardized report helping enterprises in how to report their commitment with SD [12]. It was created as a common reporting framework covering the entire organization. The GRI specifies directives in which organizations report their performance based on SD indicators related to economic, social and environmental aspects [12,13]. The GRI Reporting Framework contains general and sector-specific content that has been agreed upon by a wide range of stakeholders around the world to be generally applicable for reporting an enterprise's SD performance [12].

Actually EAF do not fully support the implementation of ISO Standards and GRI, and it is the responsibility of the enterprise itself to create the full scope and controls to deal with it.

\section{Enterprise Engineering with GERAM}

Enterprise modeling is considered the principal item of Enterprise Engineering, because the modeling process creates a model that represents all (or part of) enterprise operations. This model allows simulations and evaluations that conducts the enterprise operation to an optimized structure, behavior, and content $[14,15]$. Reference Architectures for modeling and engineering enterprises aim to provide a 'map' with which is possible to design business processes and other systems of a company $[16,17]$.

Enterprise Architecture Frameworks (EAF) are intellectual paradigms which facilitate the analysis, discussion and specification of a given area, providing a base and a way to understand, design, and discuss a matter [18]. The main goal of an EAF is to define and implement enterprise strategies, being a guide to its evolution, balancing all needs and limitations to achieve an acceptable and feasible project $[19,20]$. Several EAF were proposed such as CIMOSA, ARIS, TOGAF, PERA and GERAM.

GERAM (Generalized Enterprise Reference Architecture and Methodology) uses the best parts of GRAI-GIM (Graphs with results and activities interrelated), PERA and CIMOSA architectures to provide a reference to the enterprise integration area. GERAM provides a description of all components recommended for an Enterprise Engineering and a collection of tools and methods to perform enterprise design and changes with success. It also considers enterprise models as an essential approach to support EE and integration [21,22,23,24].

GERAM has nine main components. The most important component is the Generic Reference Architecture - GERA, which defines a set of concepts to be used in Enterprise Engineering, as enterprise entities, life cycle, life histories of 
enterprise entities, and others (see Fig. 1 adapted of IFIP/IFAC [21] with a new view proposed in this work).

GERAM defines again as components the Enterprise Engineering Methodologies (EEM), and distinguishes them from Enterprise Modeling Languages (EML) used by the methodology to describe aspects of the enterprise, like the structure, content, and behavior of the entities to be modeled. The modeling language semantics may be defined by anthologies, meta-models and glossaries that are collectively called Generic Enterprise Modeling Concepts (GEMC). Partial Enterprise Models (PEM), which are reusable models of human roles, processes and technologies, are used to facilitate modeling. Enterprise Engineering Tools (EET) supports the methodologies and languages used for enterprise modeling. The modeling process results in particular Enterprise Models (EM) that represent all or part of the enterprise's operations (manufacturing or services tasks), its organization and management, and its control and information systems. These models can be transformed into an Enterprise Operational System (EOS), or be used to perform simulations, and to promote changes in the enterprise. The EOS is a set of enterprise modules (EMO) that support the operational use of enterprise models. EMO provide prefabricated products like human skills, common business procedures or IT infrastructure services, used as components in implementation of the EOS [21].

Users of other reference architectures can use GERAM as a benchmark, and identify what to expect from the particular architecture chosen, when their features are compared $[22,25]$.

The component GERA recommends the modeling of the enterprise according to four basic and complementary viewpoints (other views can be defined) (see GERA adapted in Fig. 1):

- Function view, which represents the functionality and behavior of the company (i.e., events, activities and processes) including temporal and management of exception aspects;

- Information view, which represents the objects of the enterprise and its information elements;

- Resources view, which represents the means of the enterprise, its capabilities and management;

- Organization view, which represents organizational levels, authorities and responsibilities.

Despite its comprehensive support to enterprise common aspects, a few requirements related to SD are explicitly supported by GERA originally.

\section{Analysis and Discussion}

With the objective of analysis and integrate sustainability requirements into Enterprise Architectures, based on literature review done in Section 2 and 3, it was possible evaluate intersections of covered concepts by a cross analysis of standards and frameworks with components of an enterprise architecture and 


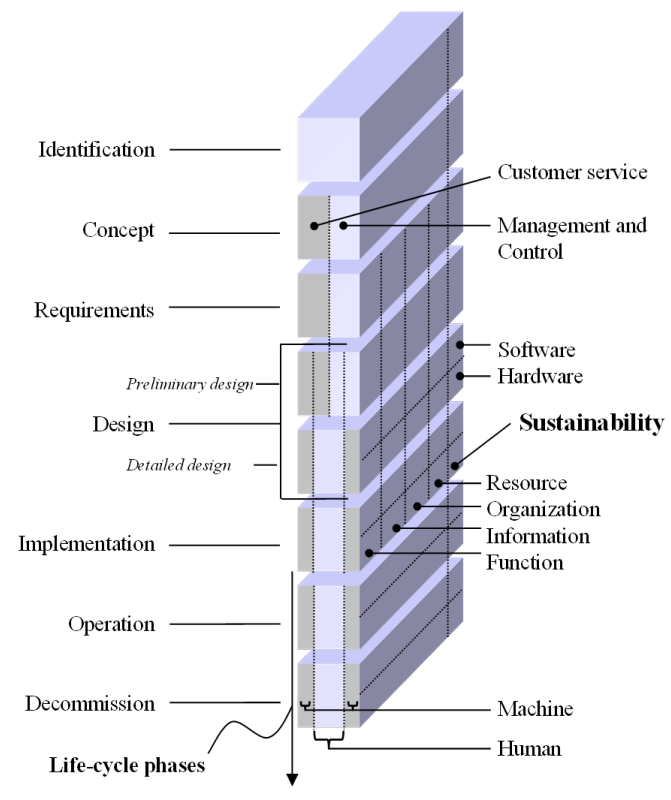

Fig. 1. Proposal for extending GERA with a Sustainability View. (Source: adapted of $[21])$.

requirements for sustainable development (Table 1). It was built and structured with a Likert scale according to the literature review conducted by the authors to demonstrate the existing comprehensive relationships between the concepts presented by the ISO standards and the GRI and its agreements with the requirements needed by SD and components of a EAF.

ISO 9001 helps companies seeking to maintain their image while serving customers concerned about the environmental impacts the production of their products causes the environment. The standard also provides guidelines on developing, implementing, maintaining and improving the quality of organizational processes. ISO 14001 increases the awareness of the enterprise and its involvement in environmental practices through continuous improvement processes and programs related to the management system provided by the standard. ISO 14001 has been used as an important factor in selecting potential suppliers, because it requires the entire supply chain to be committed to SD by acquiring and producing green products. ISO 26000 has guidelines to implemented social requirements, then, the enterprise can reach a given level of social responsibility.

GRI report, one of the main performance indicators for evaluating the enterprise's SD commitment today can be used to create guidelines within the GERAM structure, helping the creation and evaluation of SD indicators during the enterprise's operation. With this, a SD perspective can easily analyze all the enterprise process and products involved. Furthermore, reporting all the efforts 
done to achieve the SD commitment to costumers, governments and stakeholders.

GERAM was proposed for analyzing and developing the extensions to integrate SD requirements due the fact that all Enterprise Architecture can be assessed and broken down according to GERAM structure [21,23,24].

The cross analysis of the table 1 shows gaps and opportunities to incorporate sustainability into components of an enterprise architecture.

GERAM components touch various aspects of SD requirements with different perceptions and abstractions. The economic aspect is addressed by GERAM [21]; however it focuses on investment, different from SD, which encompasses society as part of the economic dimension. As for the social aspect, the architecture considers only workers' care while conducting their technical work, which covers their skills to perform the function and show the result of that work (i.e. the product or service they transform). The environmental aspect is minimally addressed by GERAM architecture. Nonetheless, it is possible to complement GERAM economic, social and environmental aspects in order to reconcile with the requirements of SD.

Table 1. Analysis of intersections of covered concepts.

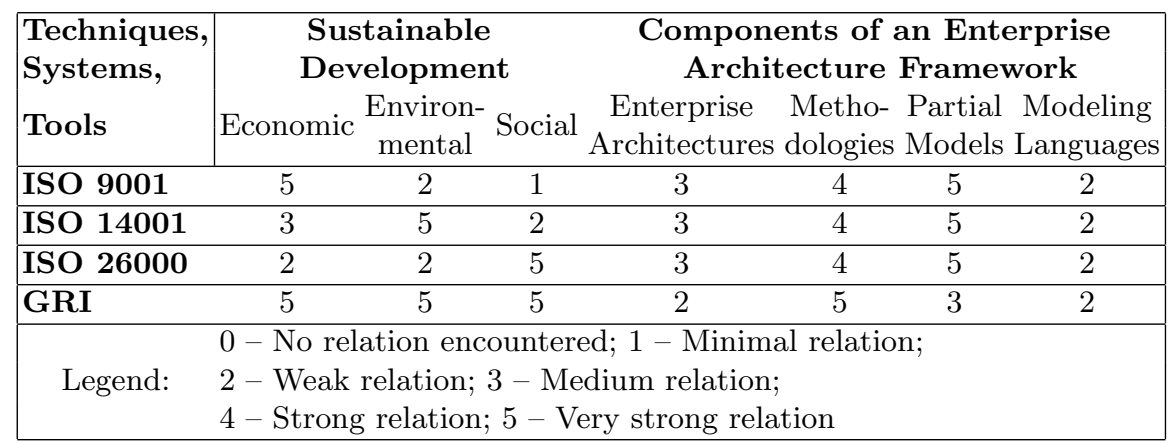

Analyzing Table 1, it is possible to propose improvements in the ability of a EAF (as GERAM) to design enterprises, supporting the goals and requirements of SD based on presented ISO Standards and GRI. Some guidelines are proposed:

- Enterprise Architectures (as GERA) could include a new view of Sustainability in its structure (Fig. 1);

- Enterprise Engineering Methodologies (EEM) could integrate in its phases or steps techniques, practices and tools systems related to ISO standards and frameworks as GRI;

- Some Partial Enterprise Models (PEM) related to sustainability already exists and can be identified in the literature. Thus, these, ISO standards and sustainability 
- frameworks could be merged in partial models and be available in Enterprise Engineering Tools (EET) to facilitating particular sustainable Enterprise Models (EM);

- To describing partial or particular model, Enterprise Modeling Languages (EML) need to be extend to express the related sustainability aspects and requirements.

In this work, GERAM is presented as the basis and reference for developing academic or corporate works for extending SD requirements to enterprise modeling and engineering, because these efforts may be mapped in other framework architectures later.

For example, a possible proposal is shown in Fig. 1, with the creation of a new view in GERA named Sustainability, that highlight the need to include concepts of SD, as ISO standards and GRI.

\section{Final Considerations}

Enterprise architectures, methodologies and tools for Enterprise Engineering must support the integration of various issues to be addressed in an organization, such as its information system, factory layout, logistics systems, quality system, cost, as well as describe human and organizational aspects. However, the available EAFs do not address accordingly all SD requirements adequately in a systemic and integrated way.

This works presents some guidelines to extend components of GERAM with ISO standards and frameworks related to sustainability.

A new modeling view was proposed in GERA. In this sense, when the requirements of ISO Standards are transported to GERA it is possible to align the requirements of SD (i.e., economic, environment and social) with the other components of GERAM.

Maybe, it is not necessary a new view in GERA, but, sustainability aspects should be considered in the others components as EM, PEM, and EML, as discussed. Details of how to integrate these techniques, systems and tools are challenges for future work.

\section{References}

1. Vernadat, F.: Enterprise Modeling and Integration: Principles and Applications. Chapman \& Hall, London, New York (1996)

2. Callahan, J.L.: Constructing a Manuscript: Distinguishing Integrative Literature Reviews and Conceptual and Theory Articles. Human Resource Development Review (9), 300-304 (2010)

3. Yadav, M.S.: The Decline of Conceptual Articles and Implications for Knowledge Development. Journal of Marketing 74(1), 1-19 (2010)

4. International Organization for Standardization: ISO 26000 - Social Responsibility, http://www.iso.org/iso/home/standards/iso26000.htm 
5. MacDonald, J.P.: Strategic Sustainable Development Using the ISO 14001 Standard. Journal of Cleaner Production 13(6), 631-643 (2005)

6. Oskarsson, K., Von Malmborg, F.: Integrated Management Systems as a Corporate Response to Sustainable Development. Corporate Social Responsibility and Environmental Management 12(3), 121-128 (2005)

7. Steele, R.: Rethinking Rio+ 20 - How ISO Contributes to Sustainable Action, http: //www. iso.org/iso/home/news_index/news_archive/news.htm?refid=Ref 1519

8. Zeng, S., Tian, P., Tam, C.: Overcoming Barriers to Sustainable Implementation of the ISO 9001 System. Managerial Auditing Journal 22(3), 244-254 (2007)

9. for Standardization, I.O.: ISO 14001 -1996 - Environmental Management Systems - Specification with Guidance for Use. Distributed through American National Standards Institute (2007)

10. Hahn, R.: ISO 26000 and the Standardization of Strategic Management Processes for Sustainability and Corporate Social Responsibility. Business Strategy and the Environment 22(7), 442-455 (2013)

11. International Organization for Standardization: ISO 26000 - 2010 Guidance on Social Responsibility. International Organization for Standardization (2010)

12. Initiative, G.R.: Sustainability Reporting Guidelines. Global Reporting Initiative, Netherlands (2011)

13. Brown, H.S., de Jong, M., Levy, D.L.: Building Institutions Based on Information Disclosure: Lessons from GRI's Sustainability Reporting. Journal of Cleaner Production 17(6), 571-580 (2009)

14. Vernadat, F.B.: Enterprise Modeling and Integration (EMI): Current Status and Research Perspectives. Annual Reviews in Control 26(1), 15-25 (2002)

15. He, D., Lobov, A., Moctezumas, L.E.G., Lastra, J.L.M.: An Approach to use PERA in Enterprise Modeling for Industrial Systems. In: IECON 2012-38th Annual Conference on IEEE Industrial Electronics Society. pp. 4196-4203. IEEE (2012)

16. Mertins, K., Jochem, R.: Architectures, Methods and Tools for Enterprise Engineering. International journal of Production Economics 98(2), 179-188 (2005)

17. Minoli, D.: Enterprise Architecture A to Z: Frameworks, Business Process Modeling, SOA, and Infrastructure Technology. CRC Press (2008)

18. Vernadat, F.: Interoperable Enterprise Systems: Architectures and Methods. IFAC Proceedings Volumes 39(3), 13-20 (2006)

19. Lankhorst, M., Iacob, M.E., Jonkers, H., van der Torre, L., Proper, H., Arbab, F.: Enterprise Architecture at Work: Modeling, Communication, and Analysis. Springer, Berlin, (2009)

20. Wegmann, A.: On the Systemic Enterprise Architecture Methodology (SEAM). In: Proceedings of the 5th International Conference on Enterprise Information Systems. pp. 179-188. No. 483-490, ICEIS (2003)

21. Force, I.I.T.: GERAM: Generalised Enterprise Reference Architecture and Methodology. IFIP-IFAC Task Force on Architectures for Enterprise Integration March Version 1(3) (1999)

22. Noran, O.: A Systematic Evaluation of the C4ISR AF Using ISO15704 Annex A (GERAM). Computers in Industry 56(5), 407-427 (2005)

23. Noran, O.: Building a Support Framework for Enterprise Integration. Computers in Industry 64(1), 29-40 (2013)

24. Vallejo, C., Romero, D., Molina, A.: Enterprise Integration Engineering Reference Framework and Toolbox. International Journal of Production Research 50(6), 1489-1511 (2012)

25. Chaharsooghi, K., Achachlouei, M.A.: Developing Life-cycle Phases for the DoDAF Using ISO15704 Annex A (GERAM). Computers in Industry 62(3), 253-259 (2011) 